\title{
SECONDARY BILATERAL SYNCHRONY ASSOCIATED TO A PARASAgITTAL TUMOR
}

\author{
CASE REPORT
}

\author{
A. CUKIERT* - G. GRONICH * - R. MARINO Jr.*
}

\begin{abstract}
SUMMARY - A 32 years old woman who had postural limbic and primarily generalized tonic-clonic seizures since the age of 11 presented to us with a CT image strongly suggestive of a mesial meningeoma near the right cingulum. Her ictal EEG pattern was characterized by regular $1.5-2.0 \mathrm{~Hz}$ sharp and slow wave complexes. A right craniotomy was performed under general anesthesia and intraoperative electroencephalographic and electrocorticographic recordings were obtained by means of scalp steel electrodes and modified cerebellar stimulation electrodes, respectively. These recordings demonstrated that surface spikes were often independent from the electrocorticographically recorded ones. Before tumor excision, electrical stimulation of the peritumoral mesial cortex resulted in an increase in the epileptic activity. The stimulation of the cavity left after tumor excision led to a prolonged electrographic seizure and neurophysiological procedures were stopped. Post-operatively, the patient has remained seizure free for 6 months and her EEG was normal. The pre-, intra- and post-operative findings in this case suggest that the gliotic peritumoral mesial cortex was at least involved in the epileptogenic process.
\end{abstract}

SUMMARY - A 32 years old woman who had postural limbic and primarily generalized tonic-clonic seizures since the age of 11 presented to us with a CT image strongly suggestive of a mesial meningeoma near the right cingulum. Her ictal EEG pattern was characterized by regular 1.5-2.0 Hz sharp and slow wave complexes. A right craniotomy was performed under general anesthesia and intraoperative electroencephalographic and electrocorticographic recordings were obtained by means of scalp steel electrodes and modified cerebellar stimulation electrodes, respectively. These recordings demonstrated that surface spikes were often independent from the electrocorticographically recorded ones. Before tumor excision, electrical stimulation of the peritumoral mesial cortex resulted in an increase in the epileptic activity. The stimulation of the cavity left after tumor excision led to a prolonged electrographic seizure and neurophysiological procedures were stopped. Post-operatively, the patient has remained seizure free for 6 months and her EEG was normal. The pre-, intra- and post-operative findings in this case suggest that the gliotic peritumoral mesial cortex was at least involved in the epileptogenic process.

Sincronia bilateral secundária associada a tumor parassagtal: relato de caso.

RESUMO - Uma paciente, com 32 anos de idade, com crises posturais e tônicoclônicas primariamente generalizadas, realizou TC de crânio que sugeria fortemente um meningioma mesial, sobre o cíngulo direito. Seu padrão elietrográfico ictal era caracterizado por complexos de onda aguda e onda lenta associadas na frequência de 1,5-2,0 Hz, difusamente distribuídos. Craniotomia frontal direita foi realizada sob anestesia geral e registros electrencefalográficos e eletrocorticográficos foram obtidos por eletrodos de aço subgaleais e eletrodos de estimu-

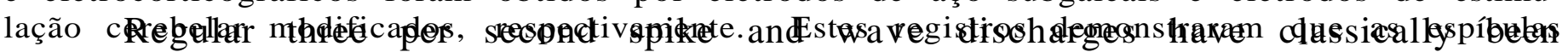

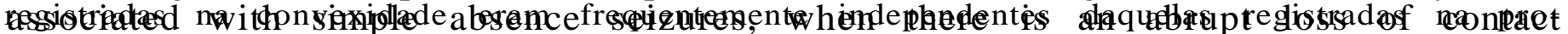

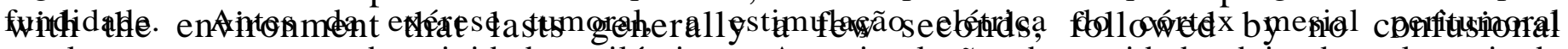

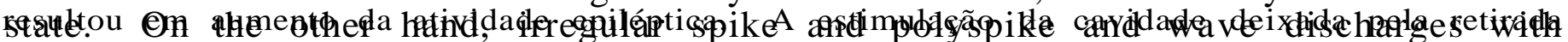

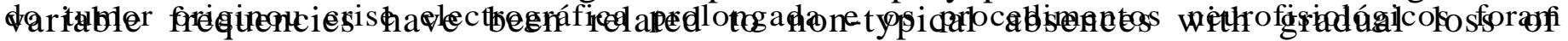

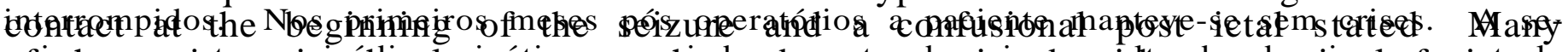

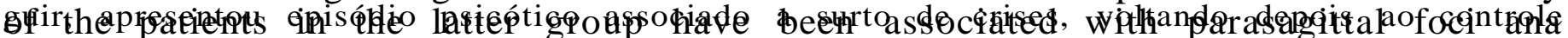

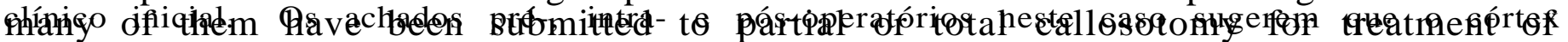

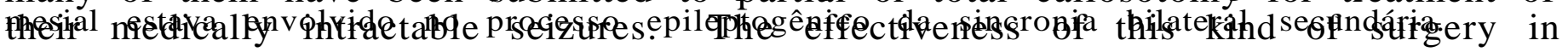

* Division of Functional Neurosurgery and Department of Neurology, The São Paulo University School of Medicine. Grants by FAPESP, FINEP, CNPq, I-LIMs.

Dr. Arthur Cukiert - Rua Baltazar da Veiga 367 apto. 151 - 04510 São Paulo SP - Brasil. 
avoiding the spread of the epileptogenic activity to the other hemisphere and lowering the epileptic objective phenomena has also been assessed elsewehere 1,6,9,13,16.

We present a case of a 32 year old woman with a parasagittal tumor and an electrographic pattern of generalized epilepsy, postural limbic seizures and no loss of consciousness who was operated upon with subsequent cessation of her seizures.

\section{CASE REPORT}

MB, a 32 years old woman began with seizures at the age of 11 . She had infrequent primarily generalized tonic-clonic seizures and some episodes that seemed to be atonic seizures at the beginning of her illness. At the age of 15 she began to have seizures in which she lost contact with the environment. Her facies was a very sad one and sometimes tears could be seen. Her shoulders were somewhat internally rotated and her arms were sustained in flexion in such a position that made the observer think that she would cry. She was unable to speak. No myoclonic movements of the eyelids could be recorded. Numbers, histories or colors shown or told her during the (attack could be reproduced soon after the end of the seizure which was characterized by no post ictal confusion. The entire episode lasted from 10 to 15 seconds. Hyperventilation easily triggered these seizures. She was uncontrolled in respect to her seizures which occurred twice a day despite the use of 1.5 grams of sodium valproate and adequate doses of earbamazepine, phenytoin and primidone. The neurological examination was normal. A CT scan disclosed a right frontal parasagittal hyperdense lesion, suggestive of a meningeoma (Pig. 1). Pre-operative EEGs were characterized by a normal background activity with diffuse bursts of sharp and slow wave complexes at a frequency of 2 to $3 \mathrm{~Hz}$, with a higher amplitude over the left hemisphere. During the seizures, regular 1.5 to $2.0 \mathrm{~Hz}$ sharp and slow wave complexes were recorded after a train of spikes over the right frontal region (Fig. 2).

This patient underwent a right frontal craniotomy under general anesthesia with intraoperative electroencephalographic and electrocorticographic monitoring. The surface EEG was recorded by means of steel needle electrodes placed subcutaneously over both anterior parasagittal, left temporal and right prefrontal and temporal regions. The electrocorticogram was obtained with two modified cerebellar stimulation electrodes placed over the right

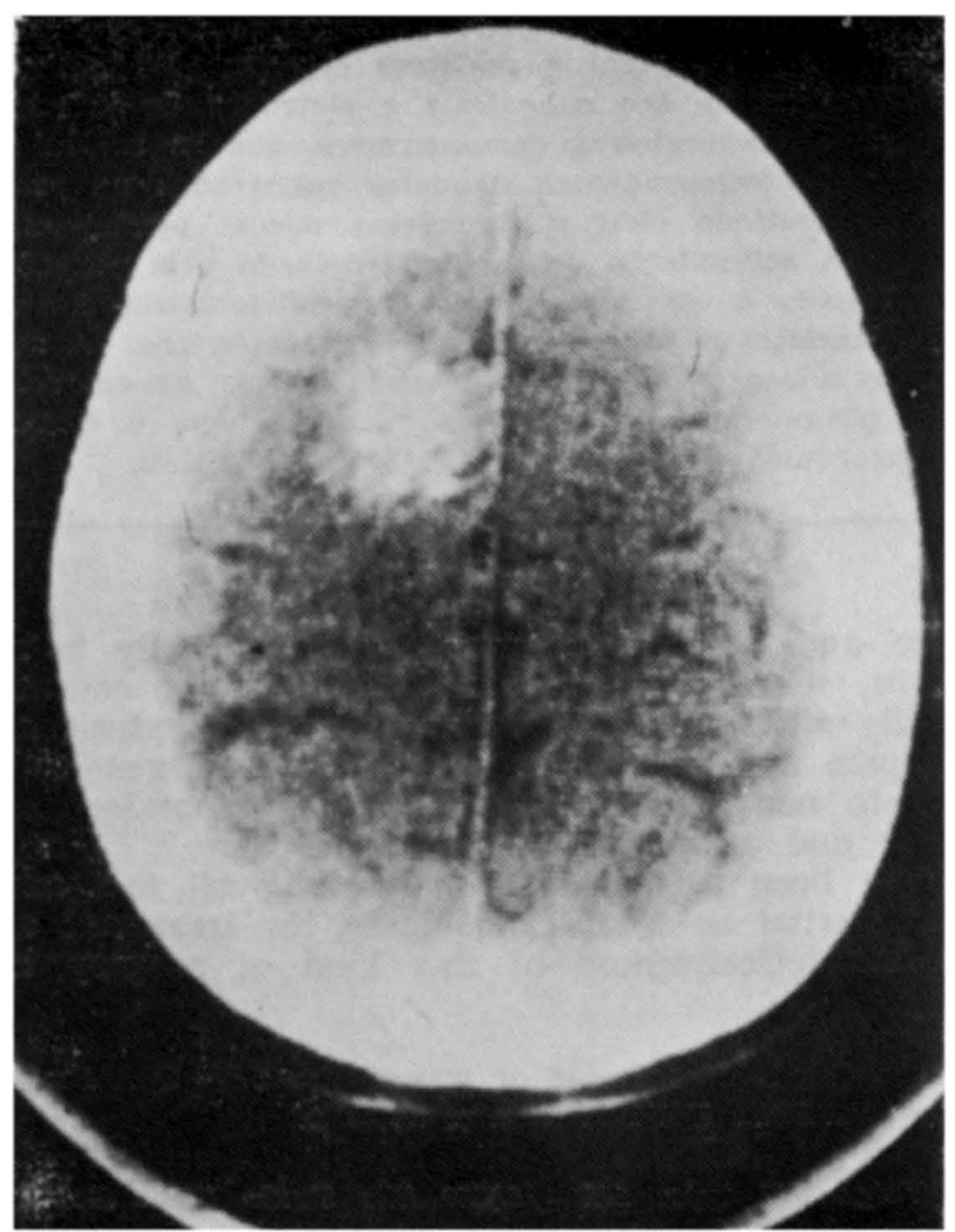

Fig. 1 - The CT scan showing the parasagittal lesion suggestive of a meningeoma. 


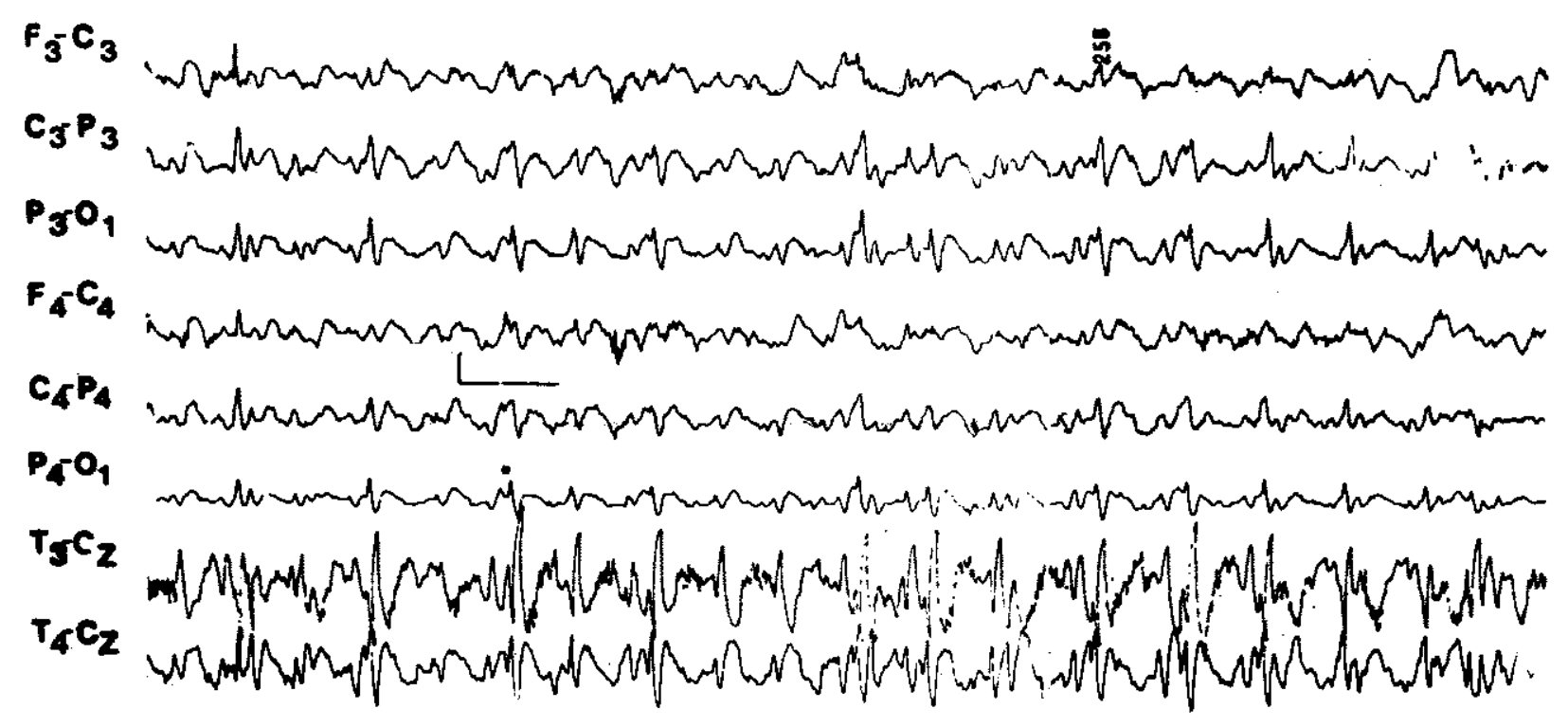

Fig. 2 - Ictal EEG pattern showing a train of spikes over the right frontal region followed by regular bilateral and symchronous 1.5-2.0 He sharp and slow wave complexes. .Vertical bar $=25 u \mathrm{~V}$; horizontal bar $=1 \mathrm{sec}$.

mesial region, one over the tumor surface and the other lying on the mesial frontal cortex. Before tumor excision, independent spikes on the surface EEG and electrocorticogram could be seen. Electrical stimulation with pulses with a frequency of $60 \mathrm{~Hz}$, duration of $1 \mathrm{~ms}$ and amplitude of 1 Volt was performed for 5 seconds each time by means of the same electrodes described. The stimulation on the tumor surface caused an increase in the number of sharp waves with a latency of 10 seconds. This phenomenon! was very transient. The stimulation of the mesial cortex posterior to the tumor disclosed an increaese in that same type of activity without any latency (Fig. 3). Stimulation of the mesial cortex anterior to the tumor, the frontal convexity and the cingulate gyrus did not alter the basal activity. After removal of the tumor there was a clear increase in the amount of irritative discharges which were more diffuse and frequent and characterized by bursts of sharp waves, spikes and polyspikes-slow waves complexes, predominantly over the central areas. Stimulation of the cavity left after the tumor removal, which was covered by intense peritumoral gliosis, gave rise to tan electrographic seizure after 30 seconds. Desynchronization of the cerebral activity followed by intense irritative discharges with sharp waves, spikes and polyspikes either associated or not to slow waves was recorded (Fig. 4).

A post-operative CT scan showed a complete removal of the tumor. An EEG performed 5 months later was normal and the patient was seizure free. Two months later, she developed a psychotic episode associated to a cluster of seizures which remitted with standard neuroleptic drugs. One year afterwards she is controled in relation to her seizures under high dose valproate therapy. Pathological examination of the tumor that was located on the right mesial surface with its lower border over the cingulate gyrus and its superior border $3.5 \mathrm{~cm}$ far from the frontal convexity, proved it to be a meningeoma.

\section{COMMENTS}

The patient was presented to us as having medically intractable «absence» seizures. Valproate, phenytoin, carbamazepine and primidone in adequate doses, in mono- and polytherapy had been tried previously.

GloorS discussed the usefulness of the term consciousness in epilepsy. He was able to gather a few examples of reported seizures with a spike and wave EEG pattern where consciousness was not completely lost. In those cases, aphasia and a motionless behavior were the main points disturbing the contact with the environment. Our patient had no loss of consciousnes although she was unable to contact during a seizure due to a sustained tonic posture. The seizures also showed some limbic features characterized by the appearance of a «sad facies» many times including tear drogs. The EEG and clinical pictures pointed to a parasagittal focus near limbic structures, particularly the cingulate gyrus where the tumor has later been found $2,4,7,8,10-12,14,15$.

Intraoperative electrocorticography confirmed the presence of the parasagittal focus around the tumor and post-operative follow up confirmed the cessation of 


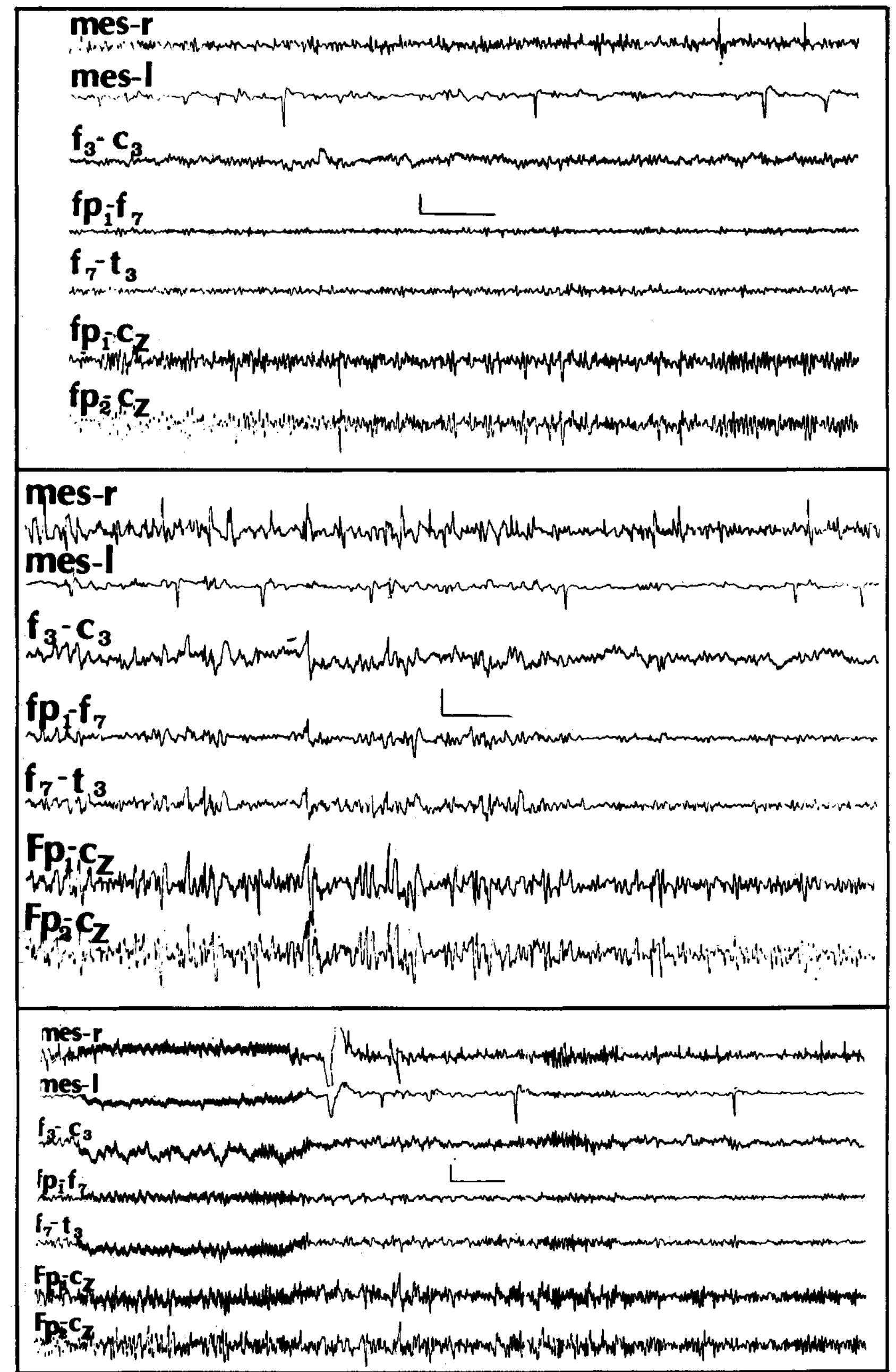

Fig. 3 - Above: pre-stimulus basal recordings showing surface spikes independent from the electrocorticographically recorded ones.

Middle: pattern of increased irritative activity after stimulation of the tumor with a latency of $10 \mathrm{sec}$.

Below: results of stimulation of the mesial cortex posterior to the tumor showing an increase in the number of sharp waves during stimulation.

Vertical bars $=50 u \mathrm{~V}$; horizontal bar $=2 \mathrm{sec}$. 


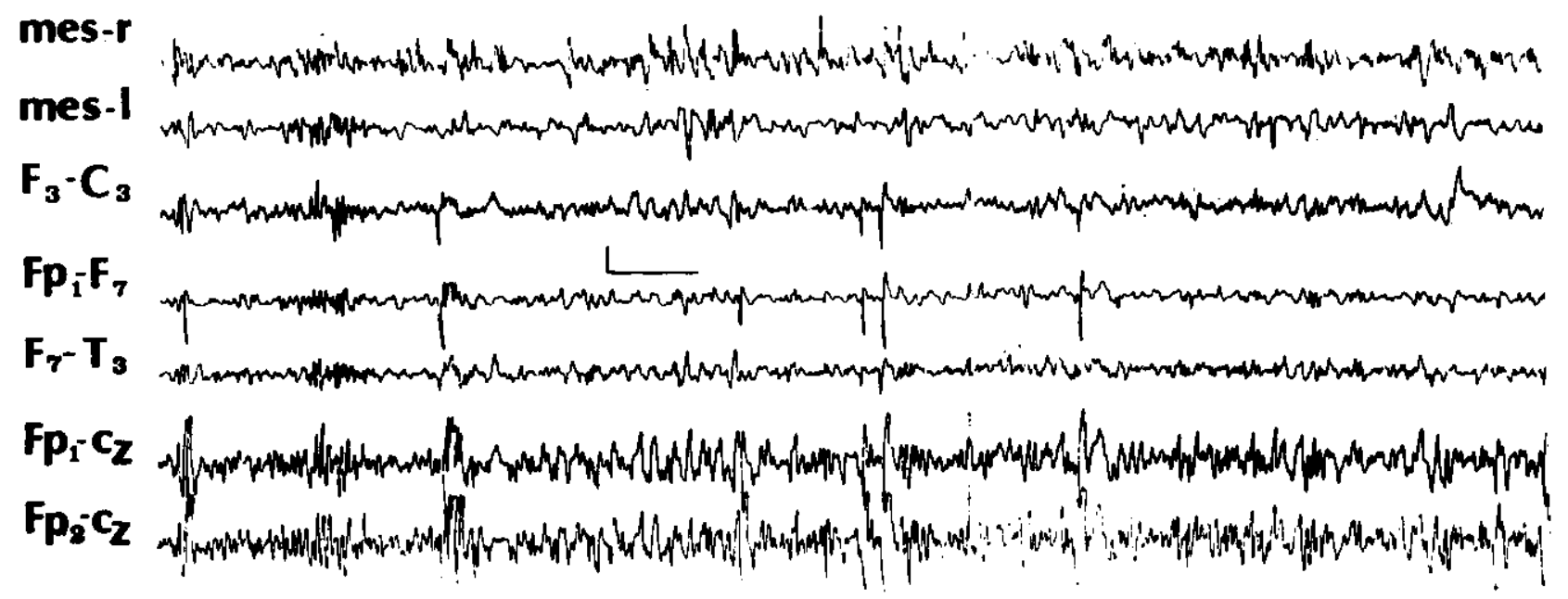

Fig. 4 - Electrographic seizure obtained after stimulation of the cavity left after the removal of the tumor, characterized by sequences of sharp waves, spikes and polyspikes associated or not to slow waves. Vertical bar $=50 u \mathrm{~V}$; horizontal bar $=2$ sec.

seizures. Cortical stimulation initiated an electrographic seizure showing that the cingulate region was at least involved in the epileptogenic process.

In summary, we present a case with clinical and electrographic generalized epilepsy patterns where a focal parasagittal lesion has been found. Surgical excision of the abnormal tissue and its surrounding gliosis has led to the disappearance of the seizures. The role of mesial structures in the genesis of secondary bilateral synchronies should be further studied.

\section{REFERENCES}

1. Avila JO, Radvany J, Huck FR, Camargo CH, Marino R Jr, Ragazzo PC, Riva 1). Anterior callosotomy as a substitute of hemispherectomy. Acta Neurochir 1980 (Suppl) $30: 137$.

2. Bancaud J, Talairach J, Morel P, Bresson M, Geier BS, Hemon E, Buser P. «Generalised» epileptic seizures elicited by electrical stimulation of the frontal lobe in man. Electroenceph Clin Neurophysiol 1974, $37: 275$

3. Commission on Classification land Terminology of the ILAE. Proposal for revised clinical classification of epileptic seizures. Epilepsia 1981, $22: 489$.

4. Fegersten L, Roger A. Frontal epileptogenic foci and their clinical correlations. Electroenceph Clin Neurophysiol 1961, $13: 905$.

5. Gloor P. Consciousness as a neurologic concept in epileptology: a critical review. Epilepsia 1986, (Suppl 2) $27:$ S14.

6. Huck FR, Radvany J, Avila JO, Camargo CH, Marino R Jr, Ragazzo PC, Riva D Anterior callosotomy in epileptics with multiform seizures and bilateral synchronous spike and wave EG pattern. Acta Neurochir 1980, (Suppl) $30: 127$.

7. Kennedy WA. CLnical and electroencephalographic aspects of epileptogenic lesions of the medial surface and superior border of the cerebral hemisphere. Brain 1959, 82:147.

8. Ludwig B, Ajmone-Marsan C, Van Buren J. Cerebral seizures of probable orbitofrontal origin. Epilepsia 1975, $16: 141$.

9. Marino R Jr, Ragazzo PC. Selection criteria and results of selective partial callosotomy. In Reeves AG (ed): Epilepsy and the Corpus Callosum. New York: Plenum Press, 1985, p 281-301.

10. Mazars G. Criteria for identifying cingulate epilepsies. Epilepsia 1970, 11:41.

11. Pedley TA, Tharp BR, Herman K. Clinical and electroencephalographic characteristics of midline parasagittal foci. Ann Neurol 1981, 9:142.

12. Ralston BL. Cingulate epilepsy and secondary bilateral synchrony. Electroenceph Clin Neurophysiol 1961, $13: 591$.

13. Spencer SS, Spencer DD, Glaser GH, Willianson PD, Mattson RH. More intense focal seizure types after callosal section: the role of inhibition. Ann Neurol 1984, 16:686.

14. Tharp BR. Orbitofrontal seizures: an unique electroencephalographic and clinical syndrome. Epilepsia 1972, $13: 627$.

15. Tukel K, Jasper H. The electroencephalogram in parasagittal lesions. Electroenceph Clin Neurophysiol 1952, $4: 481$.

16. Van Wagenen WP, Herren RY. Surgical division of comissural pathways in the corpus callosum: relation to spread of an epileptic attack. Arch Neurol Psychiat 1940, 44:740. 